www.jmscr.igmpublication.org

Impact Factor (SJIF): 6.379

Index Copernicus Value: 79.54

ISSN (e)-2347-176x ISSN (p) 2455-0450

crossrefDOI: https://dx.doi.org/10.18535/jmscr/v6i9.185

Journal Of Medical Science And Clinical Research

IGM Publication

An Official Publication of IGM Publication

\title{
A Study of Benign Breast Diseases in a Tertiary Rural Hospital
}

\author{
Authors \\ Navaneethan GP ${ }^{1}$, Vasu $S^{2}$ \\ ${ }^{1}$ Associate Professor, Annapoorna Medical College and Hospitals, Salem \\ ${ }^{2}$ Post-graduate, Annapoorna Medical College and Hospitals, Salem
}

\section{Introduction}

Benign diseases of the breast are the commonest diseases affecting the female covering much morbidity and anxiety in them. Up to $30 \%$ of the women will suffer from benign breast lesions requiring treatment at some time of their life. Premenopausal women are most affected.

The most common symptoms are lump (47\%) and pain $(35 \%)$.

Aim of the treatment is to exclude malignancy and once this has been done, to treat any remaining symptoms.

Our study is intended to find out the common Benign breast diseases affecting the women in reproductive age group and the common clinical presentation and various investigations adopted and analyze different modalities of the treatment in my Vinayaka Missions Kirupananda Variyar Medical College Hospital.

\section{Objectives of The study}

To assess

A. The age groups commonly affected in various Benign Breast Diseases.

B. The clinical presentation of various Benign Breast Diseases (BBD)

C. The cytological features

D. The accuracy of FNAC in BBD
E. The efficacy of medical and surgical management of various BBD in patients who were admitted in our hospital from the period of October 2009 to October 2011.

\section{Materials and Methods}

Study Design: Prospective Descriptive Study

Study Period: October 2009 to October 2011

Study Population: 75 Cases

Type of Sample: Purposive Sample

\section{Methods}

(Parameters of Measurements)

- Age Incidence

- Clinical Features

- Quadrants Affected

- FNAC

- HPE Report

\section{Inclusion Criteria}

- Male breast (gynaecomastia)

- Pre and post menopausal women

\section{Exclusion Criteria}

- Malignancy proven with FNAC.

- Palpable axillary nodes 


\section{Observations and Results}

In our study includes 75 patients in which 62 patients are in between the age group of 15 to 45 years, 13 patients are above the age group of 45 yrs.

Table 1: Age Incidence

\begin{tabular}{|l|c|c|c|c|c|c|c|}
\hline Age in years & $<15$ & $15-20$ & $21-25$ & $26-30$ & $31-35$ & $36-40$ & $>41$ \\
\hline Fibroadenoma & - & 2 & 17 & 8 & 10 & 6 & 6 \\
\hline Fibrocystic disease & - & - & - & - & - & 1 & 10 \\
\hline Breast abscess & - & 1 & 2 & 1 & 1 & - & - \\
\hline Fibroadenosis & - & - & 1 & - & 2 & 1 & - \\
\hline Phylloides tumour & - & - & - & - & - & - & 1 \\
\hline Gynaecomastia & - & 3 & - & - & - & - & 1 \\
\hline Ductal ectasia & - & - & - & 1 & - & - & - \\
\hline
\end{tabular}

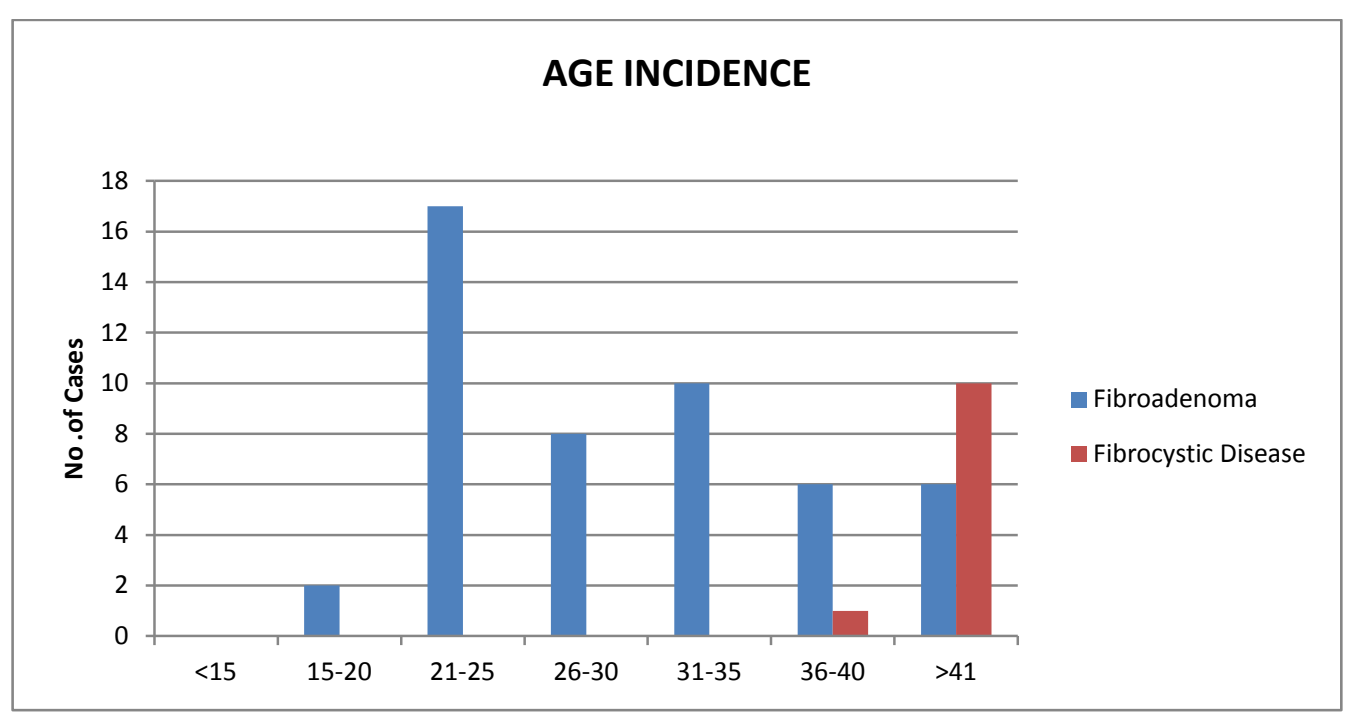

Figure 1: Age distribution

\section{Clinical Features}

- Breast lump is the main complaint of all 75 cases

- Out of 49 cases of Fibroadenoma,10 cases had vague non specific pain in the lump.

- Out of 11 cases of Fibrocystic disease,7 cases had lump with pain, not associated with menstural cycle.
Age incidence, Clinical presentation, FNAC, Excision biopsy and Management were taken into consideration \& analyzed in this study. 


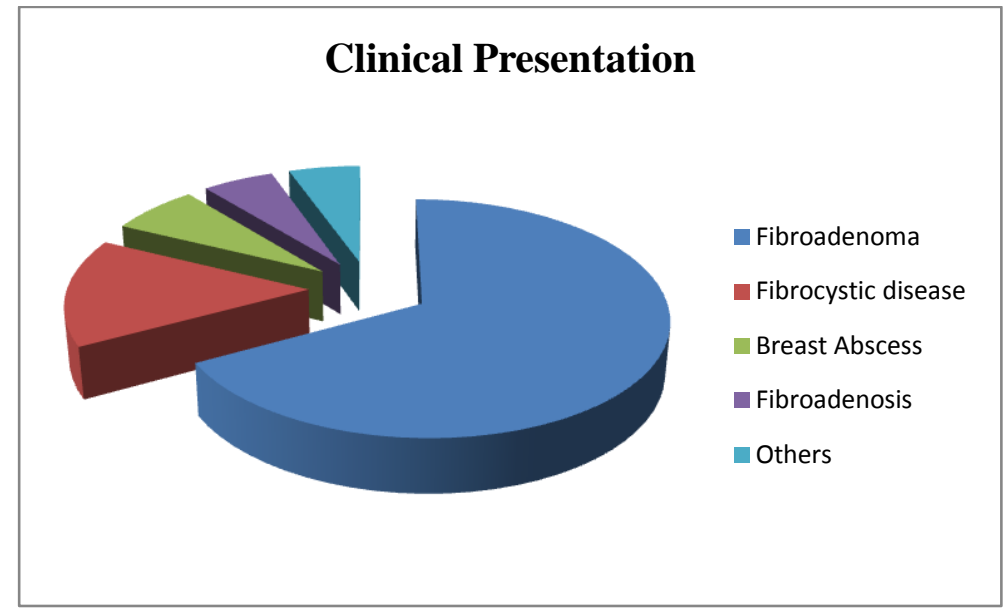

Figure 2 Clinical Presentation

\section{Investigations}

- FNAC done for all cases except Breast Abscess.

- Mammogram done for 20 cases of Fibroadenoma, 11 cases of Fibrocystic disease and 4 cases of Fibroadenosis.

- USG done for all Breast Abscess patients.

\section{Management}

- Excision biopsy was done in all cases of Fibroadenoma in which 2 cases associated with Fibrocystic disease by HPE.

- 11 cases of Fibrocystic disease were treated with analgesics and anti inflammatory drugs

- 4 cases of Fibroadenosis were treated conservatively with analgesics and anti inflammatory drugs.

- All 4 cases of Gynaecomastia treated by Webster's Procedure.

- All 5 cases of breast abscess were treated by Emergency Incision and Drainage. Post operatively treated with antibiotics and analgesics.

- One case of Phylloides Tumour treated by Simple mastectomy.

- One case of Ductal Ectasia treated by Microdochectomy.

\section{Results}

1. In our study population (75 cases), total number of cases of Fibroadenoma is 49 cases,

- Right side involved in 31 cases

- Left side involved in 16 cases

- Bilateral involvement in 2 cases.

2. Fibroadenoma is commonly affected in the Right upper outer quadrant (27 cases) followed by left upper outer quadrant (14 cases), then by right upper inner quadrant (4 cases).

3. Total number of cases of Fibrocystic disease is 11 cases,

-Right side involved in 6 cases

-Left side involved in 5 cases

4. Common site of involvement is left upper inner quadrant (5 cases), followed by right upper inner quadrant (4 cases), then by right upper outer quadrant ( 2 cases).

5. 3 cases of Gynaecomastia involved in both breast and one patient involved in the left breast 6. A case of Phylloides Tumour affected in the left breast.

7. Benign breast diseases commonly occurs in the right breast (40 cases), then the left breast (27 cases) and then bilateral involvement ( 8 cases). 


\section{Results}

\section{Table 3:}

\begin{tabular}{|l|c|c|}
\hline Quadrants & Fibroadenoma & Fibrocystic Disease \\
\hline Rt upper outer & 27 & 2 \\
Rt upper inner & 4 & 4 \\
Rt lower outer & - & - \\
Rt lower inner & - & - \\
Lt upper outer & 14 & - \\
Lt upper inner & 2 & 5 \\
Lt lower outer & - & - \\
Lt lower inner & - & - \\
Both & 2 & - \\
\hline Total & 49 & 11 \\
\hline
\end{tabular}

Figure 3
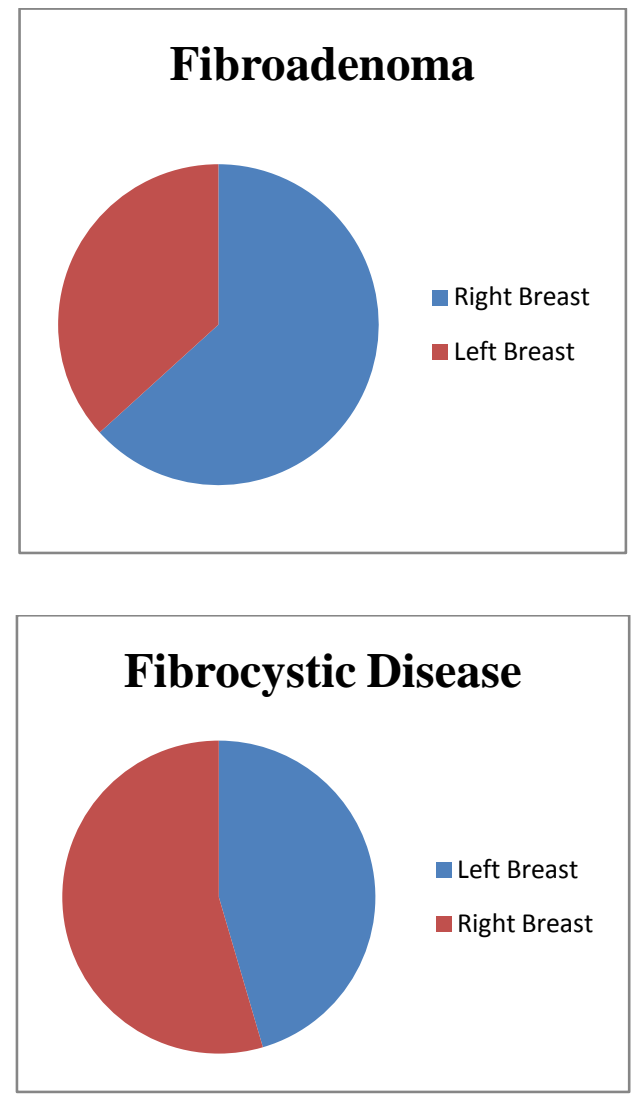

\section{Discussion}

Benign Breast lesions are commonly affecting in the reproductive age group (20-40 yrs).

In our study fibroadenoma and fibrocystic disease were common. The incidence for fibroadenoma was high in 21-25 yrs age group and fibrocystic disease was more than 45 yrs age group Dominant symptoms were lump and pain. FNAC done in all cases except breast abscess. Number of patients: 75
Table 4

\begin{tabular}{|l|c|c|c|}
\hline Disease & $\begin{array}{c}\text { Clinical } \\
\text { Diagnosis }\end{array}$ & $\begin{array}{c}\text { FNAC } \\
\text { Report }\end{array}$ & $\begin{array}{c}\text { Accuracy } \\
\text { of Report }\end{array}$ \\
\hline Fibroadenoma & 51 & 49 & $96 \%$ \\
\hline $\begin{array}{l}\text { Fibrocystic } \\
\text { Disease }\end{array}$ & 15 & 11 & $73 \%$ \\
\hline
\end{tabular}

FNAC is very efficient investigation for confirming fibroadenoma and good for fibrocystic disease.

Surgical procedures done in all cases of Fibroadenoma.

Excision biopsy with HPE stands as the ultimate investigation involved in cases of doubtful diagnosis and suspected malignancy which has $100 \%$ accuracy.

Mammogram is $100 \%$ accuracy in the diagnosis of fibroadenosis.

USG is $100 \%$ accuracy in the diagnosis of breast abscess.

\section{Conclusion}

Our study proved that benign lesions are the commonest lesions of female breast especially of the reproductive age group (15-45yrs).

Fibroadenoma is the commonest followed by fibrocystic disease.

Right upper outer quadrant is the commonest area affected in fibroadenoma.

Left upper inner quadrant is the commonly involved in fibrocystic disease.

Pre menopausal women commonly affected with benign breast disease.

Lump \& pain are the commonest symptoms.

FNAC is the single most useful investigation with high diagnostic accuracy in experienced hands. The accuracy in Fibroadenoma is $96 \%$ \& in the fibrocystic disease is $73 \%$.

Excision biopsy is the treatment of choice in fibroadenoma.

HPE report should be obtained if there is disagreement between cytological and clinical assessment.

In our study results are correlating with the literatures. 


\section{References}

1. Adele J.S.Miller T.R. Goodson W.M et al FNA for palpable breast masses. A program for staged implementation Arch. Surgery $1983 ; 118,859$.

2. Ackermans surgical pathology : Juanrosai $19897^{\text {th }}$ Edition.

3. Bailey and Loves short practice of surgery $22^{\text {nd }}$ edition.

4. Breast disease - contemporary issues in $\mathrm{O}$ $\& \mathrm{G}$.

5. Schwartz's Principles of surgery $8^{\text {th }}$ edition.

6. Dehn TCB Clark J. et al., FNAC with immediate reporting in the outpatient diagnosis of breast disease. Annals of Royal college of Surgeons of England 1987, 69: 280-282.

7. Canj P.J. Madden DU et al., were for conservative management of selected cases of fibroadenoma of breast - British Journal of Surgery 1987; 74:857.

8. Dent DM and Cent PJ Fibroadenomas year book of surgery 1991; 155-165.

9. England PC Skimer LG et al., Sex hormones in Breast diseases British Journal of Surgery 1975; 62: 806-809.

10. Du Pont WD of Page DL risk factor for Breast cancer in women with proliferative breast disease New England journal of medicine 1985; 312: 140-157.

11. Essential surgical practice $-A$ cuscheiri $3^{\text {rd }}$ Edn. 1996.

12. Koss L.G. Diagnostic cytology and its histopathologic basis, Ed .3,1979.

13. Ester NC mastodynia due to fibro cystic disease controlled with thyroid hormone. American Journal of Surgery 1981; 142: 764-766.

14. Goodson et al., three year follow up of being FNAB of the breast. American Journal of Surgery 1987; 154: 58-61.
15. Magensen CD disease of breast $19803^{\text {rd }}$ Edn. 1050.

16. Hughes LE Mansel RE and et al., and new preventive in pathogenesis and nomenclature of BBD lancet 1987: 316.

17. Love SM et al., Fibrocystic disease of breast a non disease of New England Journal of Medicine 1982; 307-1010.

18. Maddox PR et al., non cyclical mastalgia. Classification and treatment. British Journal of Surgery1989; 76:901404.

19. Nicholson, S., et al., Use of FNAC with immediate reporting in diagnosis of breast disease. British Journal of Surgery 1988; 75: 847-850.

20. Pathologic basis of Disease- Robbins, Cotran, Kumar.

21. Preece PE. et al.,mastalgia and total body water. British Medical Journal 1975; 4: 498-500.

22. Preece PE. et al.,Mastalgia: Psychoneurosis of organic disease. British Medical Journal 1978. Pp.29-30.

23. Pye JK, Mansel RE and Hughes LE Clinical Experience of Drug Treatment for Mastalgia, Lancet 1985(iii) pp. 373-377.

24. R.J. Last - Anatomy regional and applied.

25. Sabiston Text Book of Surgery -2000 edn.

26. Small Wood J. et al., Vitamin B6 in treatment of premenstrual Mastalgia, British Journal of Clinical Practice 1986, 40: 532-534.

27. Synopsis of Surgical Anatomy- Mcgregor.

28. Walters, TK., Zuckerman, J., Nisbet Smith A. et al., FNAB in diagnosis and management of fibroadenoma of the breast. British Journal of Surgery 1990; 77:1215-1217.

29. Recent advances in surgery Vol .21, 1998.

30. Oxford text book of surgery $2^{\text {nd }}$ edition, 2000. 